\title{
Feminidades $y$ masculinidades en la Historiografía de Género
}

FICHA BIBLIOGRÁFICA

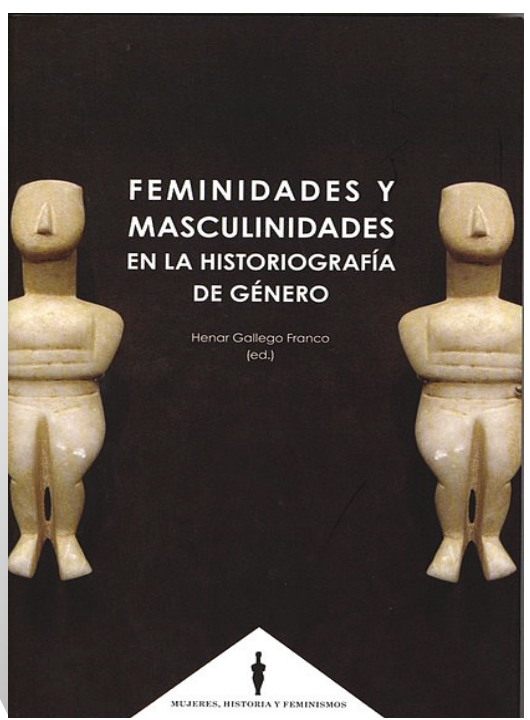

Henar Gallego Franco (ed.), Feminidades $y$ masculinidades en la Historiografía de Género, Granada, Editorial Comares, colección Mujeres, Historia y Feminismos, 2018, 233 págs. ISBN 978-84-9045-701-6.

Ana Vargas Martínez I Universidad Carlos III de Madrid

EL VOLUMEN QUe AQUí SE PRESENTA bajo el título Feminidades y masculinidades en la historiografía del género recoge las aportaciones del sexto Seminario Internacional de Investigación organizado por la Asociación Española de Investigación Histórica de las Mujeres (AEIHM), cuidadosamente reunidas por su editora, Henar Gallego Franco. Los seminarios de investigación, con el nombre de Seminario Internacional Historia y Feminismo se celebran bianualmente, constituyen uno de los encuentros científicos en los que se tratan aspectos centrales de las prácticas historiográficas desde una perspectiva multidisciplinar en el campo 
de la Historia de las Mujeres y del Género. Se ofrece una base para la reflexión en profundidad sobre dichos aspectos, abordando, además, cuestiones metodológicas y teóricas que suponen un enriquecimiento para el trabajo de investigación histórico. La presente publicación constituye una relevante aportación para la construcción de una Historia crítica, una historia de mujeres y hombres, que nos ayuda a conocer, explicar y entender mejor nuestro presente. En ella se abordan dos campos temáticos estrechamente relacionados y que han sido intensamente revisados en los últimos tiempos desde los estudios de expertas y expertos en la Historia de las Mujeres y del Género. Desde diferentes perspectivas y contextos, los estudios reunidos en este libro exploran, analizan y reflexionan sobre nuevas formas de reinterpretar y valorar los conceptos de feminidad a lo largo de la historia así como los nuevos conceptos acuñados en las últimas décadas desde los cada vez más en boga estudios de la masculinidad. Todo ello expuesto con el rigor y la calidad científica que, como viene siendo habitual, es una señal de identidad que caracteriza los seminarios y publicaciones de la AEIHM.

El contenido del libro está compuesto por cuatro partes, en las que se reúne un total de nueve textos, correspondientes a las tres Sesiones y la Mesa Redonda en la que se dividió el Seminario. Se recoge también los debates que tuvieron lugar al final de cada una de las sesiones y de la mesa redonda incluyendo sus transcripciones, cumpliendo así con uno de los objetivos de los Seminarios Internacionales de Investigación: promover el debate científico.

La primera parte, bajo el título de Feminidades y masculinidades no normativas, se abre con un interesante estudio entorno a las feminidades fuera de la norma en la Grecia helenística donde su autora, María Dolores Mirón Pérez, hace un sugestivo análisis mostrando como el género está claramente interrelacionado con otros factores como la identidad, el privilegio social o el poder. «Una mujer fuera de norma sería ante todo una que ejerciera poder político y /o libertad sexual» (pág. 8), en ese sentido, la autora muestra y analiza a lo largo de su artículo distintos ejemplos, entre otros, refiere el de las amazonas, en torno a las cuales se configura todo aquello que los varones griegos más podía temer en las mujeres. En un marco histórico completamente diferente, en la contemporaneidad, un segundo artículo trata sobre las feminidades y masculinidades contestatarias presentes en la novela de Lluis Llach, Memoria de unos ojos pintados (2012), centrada en la Barcelona de los años veinte y treinta del siglo veinte, la Guerra Civil y el franquismo. Richard Cleminson, autor del estudio, realiza una sugerente lectura de la obra y un interesante análisis de las diferentes expresiones de masculinidad (como es el amor entre hombres, parte central de la novela) y feminidad no normativas en la novela de Llach.

Con el título de Identidades de género y diferencias sociales se recogen los dos artículos presentados en la segunda sesión en los que se aborda la jerarquización social como elemento constitutivo de las identidades sexuales de feminidad y masculinidad a lo largo de la historia. En el primero, centrado en el mundo medieval, su autor, Rafael Mérida Jiménez, hace una rica revisión crítica de la historiográfica relacionada con el estudio de las masculinidades en el medievo hispánico, centrando su atención en los casos de sodomía y su entorno social. Un tema que ha regresado con nuevos bríos a la investigación académica del Medioevo europeo. En el segundo estudio, llevado a cabo por Mónica Bolufer Peruga, se expone igualmente una detallada revisión historiográfica en este caso de uno de los temas más singulares de la 
Historia de las Mujeres y del Género en Europa como es la Querella de las Mujeres. Un tema clásico, pero que no deja de perder interés, sino todo lo contrario, pues sigue teniendo la capacidad de conectar con inquietudes del presente y de renovarse con la incorporación de nuevos métodos, análisis, enfoques y preguntas que, desde una óptica multidisciplinar, hace que continúe siendo un tema de gran potencial como espléndidamente muestra la autora a lo largo del artículo.

Feminidades y masculinidades en los procesos de construcción nacional es el título de la tercera parte compuesto igualmente por dos estudios en los que se analiza la relación entre identidad de género y nacionalismo, una cuestión de gran interés y que ocupa un lugar central en la historiografía del género del mundo contemporáneo. ¿Qué mujeres para qué España?: feminidad y nación en el feminismo español (1900-1923) es el estudio con el que se abre esta sesión en el que su autora, Inmaculada Blasco Herranz, tomando como ejemplo la Asociación Nacional de Mujeres Españolas (ANME) (creada en 1919 y considerada como primera organización feminista en España), examina en profundidad la conexión entre mujeres, feminismo y nación. En este sentido, señala Blasco Herranz que en otros países europeos hace varias décadas que la historiografía feminista ha abierto líneas de investigación muy nítidas entorno al tema y que merece la pena explorar en España. En el segundo artículo, La masculinidad en la construcción del nacionalcatolicismo después de la Guerra Civil, Mary Vicent, su autora, explora la manera en que el modelo falangista de masculinidad, considerado como el hegemónico durante los primeros años del régimen franquista y privilegiado a lo largo del mismo, convive con otras conceptualizaciones de la masculinidad que son menos llamativas, pudiéndose considerar en su mayoría «insulsas», y haciéndose prácticamente invisibles. Asimismo, la autora plantea como pueden ser recuperados para la investigación histórica estos otros tipos de masculinidades más comunes.

A continuación se recogen tres ensayos con el título general Femenino-masculino, identidades en relación que configuran la cuarta parte del volumen y recogen las intervenciones de la Mesa Redonda con la que se finalizó el Seminario. Se inicia esta parte con la aportación de Nerea Aresti Esteban, titulada La historia de género y estudio de las masculinidades. Reflexiones sobre conceptos y métodos, que realiza una reflexión crítica en torno a los conceptos de «masculinidad hegemónica», «masculinidad moderna» $\mathrm{y}$ «crisis de la masculinidad». Centrando la atención en la última de estas categorías y sus sentidos políticos, la autora toma dos ejemplos de crisis de la masculinidad en la historia contemporánea de España, por una parte, la crisis decimonónica del 98 y, por la otra, la de los años veinte y comienzos de los treinta del pasado siglo XX. Le sigue a continuación el estudio titulado El ángel del hogar»: uso y abuso historiográfico de un arquetipo de feminidad, en el que su autora, Gloria Espigado Tocino, realiza un interesante análisis sobre uno de los imaginarios que mayor éxito ha tenido a lo largo de la historia «El ángel del hogar» y al uso que de él se ha realizado, identificando enfoques teóricos, ámbitos disciplinarios y lo que considera nudos gordianos de interpretación. Los abusos de este arquetipo femenino a los que se alude en este artículo, es lo que, señala la propia autora, le ha llevado plantear las reflexiones y escribir el presente estudio. La mesa redonda se cerró finalmente con la aportación de Geoffroy Huard, titulada Los «invertidos» en Barcelona durante el franquismo y la construcción de la memoria gay. Un 
cambio de sexo reconocido legalmente en 1977. El autor desarrolla un análisis crítico en torno a las masculinidades no normativas, el género y la clase social utilizando para ello documentación archivística como son los legajos de la ciudad de la justicia de Barcelona. Concluyendo que el conocimiento cada vez mayor de este tipo de fuentes permitirá matizar la visión que se tiene sobre la homosexualidad durante el franquismo.

Si como advierte la editora de Feminidades y masculinidades en la Historiografía de Género el objetivo primordial de los Seminarios Internacionales de la AEIHM, y su posterior publicación, es la de ofrecer una base para la reflexión en profundidad sobre aspectos centrales de la práctica historiográfica en el campo de la Historia de las Mujeres y del Género, la lectora y lector podrá comprobar que se ha cumplido ampliamente con el presente volumen. 